\title{
Creativity in Science: Tensions between Perception and Practice
}

\author{
Adele L. Schmidt ${ }^{1,2}$ \\ ${ }^{1}$ Science Education, School of Education and Professional Studies, Griffith University, \\ Mount Gravatt Campus, Brisbane, Australia; \\ ${ }^{2}$ Holland Park State High School, Holland Park, Brisbane, Australia. \\ Email: aschm65@eq.edu.au \\ Received September 29 $9^{\text {th }}$, 2011; revised October 30 ${ }^{\text {th }}$, 2011; accepted November 14 $4^{\text {th }}, 2011$.
}

\begin{abstract}
Many countries are reviewing science education programmes and implementing new pedagogical paradigms aimed at reversing a trend of declining enrolments. A key factor in this decline is a public perception that science is not a creative endeavour. Attempts to reframe public perception tend to focus on primary and secondary schooling, but do little to address ongoing declines in quality and originality of intellectual output beyond the high-school environment. To overcome systemic devaluation of science requires appreciation of the complex, dynamic, and often stochastic, interplay of sociocultural, psychological and cognitive factors that drive human creativity. Viewing creativity from this perspective reveals tensions between perception and practice that limit opportunities for students, science educators and scientists. Resolving the tension requires integration of developmental, psychometric and sociocultural discourses of creativity in ways that generate opportunities for individuals at all levels of education and practice to: 1 ) acquire a high level of domain-specific knowledge; 2) practise application of that knowledge in developing solutions to problems across a gradient of difficulty and; 3 ) be challenged to integrate their knowledge of science with their knowledge of other fields to pursue and solve problems with personal relevance.
\end{abstract}

Keywords: Science Education, Teaching for Creativity, Contextual Science, Context-Based Learning, Inquiry-Based Learning, Creativity, Scientific Creativity

\section{Introduction}

The importance of sociocultural influences in contextualising and contemporising teaching and learning is a recurrent theme in all areas of education, but has particular relevance for science subjects (Barrow, 2006; Carter, 2008). Although science is recognised as encompassing several distinct disciplines (e.g. biology, chemistry, physics), any given domain of research and/or practice occupies a nexus between sub-fields (e.g. biochemistry, molecular biology, physical chemistry). The current pace of scientific and technological progress also means that new sub-disciplines are continually emerging (Culross, 2004; Jackson, 2004; Medina, 2006) and even those who do not go on to careers in these fields require increasing levels of scientific and technological literacy simply to participate in contemporary society (Craft, Chappell, \& Twining, 2008; Jackson, 2004).

Despite current and projected increases in employment opportunities within science and technology sectors (Jackson, 2004; McWilliam, Poronnik, \& Taylor, 2008; State of Queensland, 2002) however, enrolments in science subjects have declined dramatically over the past two decades; particularly in the enabling sciences of chemistry and physics, where student numbers are up to 21\% lower than they were in 1990 (Kessels, Rau, \& Hannover, 2006; Lyons, 2006; McWilliam, Poronnik, \& Taylor, 2008).

A key factor in this decline is a perception that science is not a creative endeavour. Surveys of student and community attitudes consistently identify rote learning and rigid, dogmatic thinking as characteristics/traits seen as essential for success in science (Barak \& Shachar, 2008; Barton, Tan, \& Rivet, 2008; Kessels et al., 2006; Latu \& Young, 2004; Lunn \& Noble, 2008; Timms, Courtney, \& Anderson, 2006). Although many individuals recognise that science has delivered significant benefits to society in the form of medical, technological and industrial innovations (Barak \& Shachar, 2008; Barton et al., 2008; Endler \& Bond, 2008; Jackson, 2004; Kessels et al., 2006; Latu \& Young, 2004; Lunn \& Noble, 2008; Timms et al., 2006), they appear unable to appreciate the rich tapestry of creative thought required to synthesise knowledge across multiple domains and design and enact experimental studies capable of extending the limits of human knowledge (Barak \& Shachar, 2008; Barrow, 2006; Barton et al., 2008; Endler \& Bond, 2008; Jackson, 2004; Kessels et al., 2006; Latu \& Young, 2004; Lunn \& Noble, 2008; Timms et al., 2006).

Attempts to broaden perceptions of science and increase student interest are increasingly incorporating new approaches to teaching and learning (Barrow, 2006; Craft et al., 2008; Endler \& Bond, 2008; Park-Rogers \& Abell, 2008). While contextualised, inquiry-based learning undoubtedly cultivates important skills such as spatial reasoning and systematic thought (Benzvi-Assarf \& Orion, 2005; Black, 2005), there is reason to believe that:

1) The wider potential of new teaching and learning strategies is diminished by emphasis on superficial engagement and a lack of attention to higher-order skills required for generation of creative solutions to scientific and technological problems (Craft et al., 2008; Endler \& Bond, 2008; Erez, 2004) and;

2) This failure to facilitate and enable genuine creativity is having a significant impact on quality and originality of intellectual output beyond the high-school environment (Australian_Research_Council, 2008; Braben, 2004; Holligan, 2005; Medina, 2006).

Although creativity is a somewhat contested notion (Boden, 2001; Csikszentmihalyi, 1990; McWilliam et al., 2008), it occupies a unique place in the scientific arena as both a requirement for future innovation and progress (Barak \& Shachar, 2008; Braben, 2004) and a personal characteristic/trait that can be developed and extended through quality education (Barak \& 
Shachar, 2008; Braben, 2004; Endler \& Bond, 2008; Holligan, 2005; Lunn \& Noble, 2008; Yager \& Akcay, 2008). To actualise the full potential of inquiry-based teaching and deliver viable, long-term solutions to problems arising from devaluation of science however, requires recognition that educational outcomes are the product of complex, dynamic, and often stochastic, interplay of sociocultural, psychological and cognitive factors.

\section{Discourses of Creativity}

Individual and societal conceptualisations of creativity are highly variable. In Western nations, creativity tends to be framed in terms of innate intelligence/ability that manifests externally as "....a product or effect that adds to the intensity and complexity of future life” (Haigh, 2007: p. 124). In contrast, Eastern conceptualisations tend to emphasize internal manifestations of creativity, such as a strong sense of ultimate reality that drives the individual to seek personal fulfilment (Seo, Lee, \& Kim, 2005). That these differences in perception are reflected in different approaches to education and training (Kim, 2005) is unsuprising, but few, if any, education professionals would view tensions between alternative perceptions of what it is, and what it means, to be creative as evidence that either, or both, culture(s) is(are) unable to support quality education programmes.

To understand the importance of maintaining and supporting multiple forms of creativity requires an understanding that teaching and learning theory draws on psychological studies of personality/character development, which may be divided into three categories: 1) psychoanalytical theories, which emphasise internal cognitive/emotional processes; 2) psychometric theories, which focus on quantification of specific personality traits/learning styles and; 3) social learning theories, which emphasise situational influences and the tendency for individuals to alter their personality and behaviour in response to changes in their social environment (Sigelman, 1999).

Translation of theories of development into teaching styles gives rise to four basic approaches: 1) a pedagogical approach, where teaching and learning are seen as processes of giving and receiving information and the emphasis is on subject-centred methods of instruction; 2) a behavioural approach, which is based on the idea that learning is achieved by establishing associations between stimuli and responses and teaching methods focus on quantifiable outcomes of instruction; 3) a cognitive approach, which emphasises internal processes such as insight and perception and teaching methods centre on the provision of experiences that will generate, or facilitate, insight and perception in the student and; 4) a developmental approach, which addresses learning as a fundamental human need and teaching strategies vary from student to student, with the emphasis on personal growth (Stredl \& Rothwell, 1987).

Merging these with contemporary creativity theory allows identification of four distinct, but overlapping, discourses of creativity (Figure 1).

\section{The Developmental Discourse: Education as Individuation}

A distinguishing feature of developmental discourses of creativity is the stipulation that all individuals are capable of at least some form of creative output.

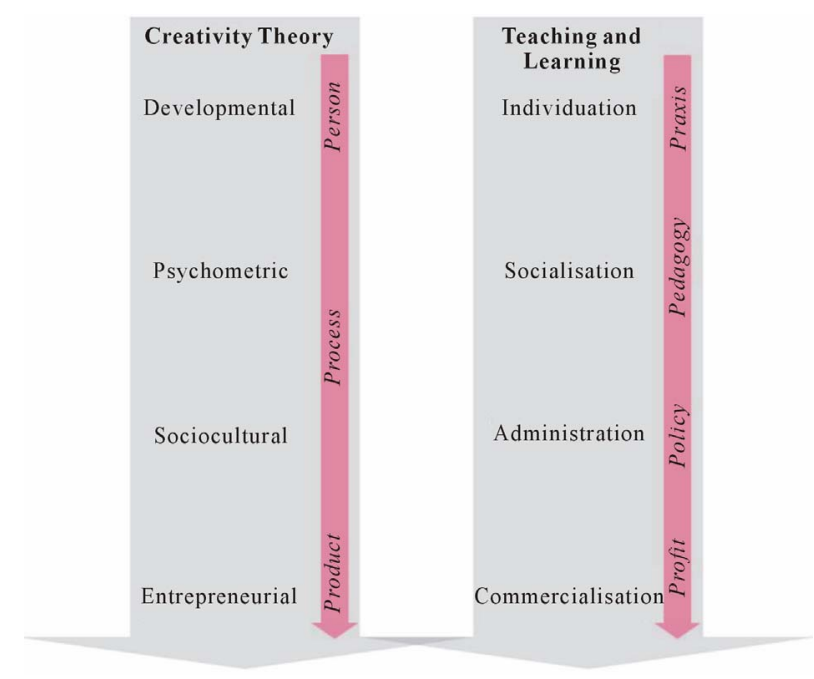

Figure 1.

Discourses of creativity.

This perception can be traced to Piaget's definition of cognition as the process which allows human beings to "think and act logically and deductively” (Sigelman, 1999: p. 171). Within Piaget's original framework, the processes of accommodation (interpretation of new experiences in relation to existing mental schema) and assimilation (modifying existing mental schema to include new information) work together to guide individuals through four developmental stages: Beginning with the sensorimotor stage, which involves development of co-ordination between sensory input and motor responses (0 - 2 years); and culminating in the formal operations stage (11+ years), which is characterised by the development of abstract thought processes that allow individuals to extrapolate their understanding of concepts and ideas to unfamiliar situations (Sigelman, 1999).

That difference in creative ability arises from differences in cognitive development of individuals is supported by empirical studies. Wu and Chiou (2008) assessed cognitive styles of 19 26 year old students and found a significant positive correlation between post-formal (relative and dialectical) cognition and performance on a standardised Divergent Thinking Test. Similarly, Runco and Okuda (1988) found that students ascertained as gifted and/or talented are able to change their mode of thought (measured as number and nature of responses) when challenged by unfamiliar, unscaffolded problems.

Although studies of this nature use only within-group comparisons, they provide support for the idea that creativity involves review of existing knowledge to identify which aspects apply in a particular instance. In adult education, the process of reviewing and selectively applying knowledge is described as transference; and is designated specific/near when the situation in which the knowledge is applied is very similar to that in which it was originally learnt or developed, and non-specific/ far when the situation in which the knowledge is applied is very different to that in which it was originally learnt or developed (Stevenson, 1994, Stevenson \& McKavanagh, 1993).

Studies comparing transference in novice and expert learners in a range of fields demonstrate that the distinction lies not in domain/content knowledge per se, but the relative complexity of cognitive schemata used to organise that knowledge, and the procedures used to retrieve and apply it when confronted with familiar and novel problems (Bruning, Schraw, Norby, \& Ronning, 2004; Meier, Reinhard, Carter, \& Brooks, 2008). Studies 
in development and moderation of artificial intelligence also provide evidence that a limited number of processes for input, output, storage and arrangement of information are sufficient to generate a wide variety of outcomes (Simon, 2001).

At the core of any developmental discourse of creativity then, is an assumption that individuals can be trained to generate creative solutions to complex and challenging problems through reconfiguration and extension of pre-existing systems of knowledge, memory, judgment, classification and categorisation (Runco \& Chand, 1995). This is consistent with Csikszentmihalyi's (1990) suggestion that there are essentially two forms of creativity: 1) big $\mathrm{C}$ creativity (BC), which describes the development of performances or products that have transformative power and; 2) little C creativity (LC), which is primarily concerned with construction of novel solutions to problems of more limited relevance. It is also compatible with Boden's (2001) extension of this classification to incorporate recognition that LC may be either combinatorial (establishing new connections between old ideas) or exploratory (operating creatively within a limited domain, or a limiting set of rules).

The existence of multiple levels of creativity justifies skillsbased approaches to education and training, including use of contextualised, problem-solving pedagogies (Barak \& Shachar, 2008; Barker, 2008; McWilliam et al., 2008). For this reason, developmental approaches to creativity can also be described as discourses of individuation (Figure 1), where the goal of education and training programmes is to support and facilitate developmental trajectories that lead to personalised learning outcomes.

\section{Limitations of the Developmental Discourse}

The limitations of developmental approaches become apparent when understanding of higher-order creativity as the ultimate stage of human cognitive development is integrated with expanding knowledge of, and interest in, neurobiology.

Evidence that the neurobiological structures and processes which determine cognitive capacity (and therefore creativity) are, to at least some extent, genetically determined (Sweller, 2009) conflicts with a growing body of data suggesting that individuals who generate creative output display complex, and highly variable, combinations of social, psychological and intellectual traits/characteristics (Calderon, Subotnik, Knotek, Rayhack, \& Gorgia, 2007; Treffinger \& Isaksen, 2005).

Difficulties arising from this varation are illustrated by a recent study of links between mathematical ability and performance in standardised creativity tests in six year old children. The results showed that females show greater ability and better results than males (Baran, Erdogan, \& Çakmak, 2009). Quantitative analysis could determine whether this is because written tests of numeracy retain a degree of dependence on reading skills, but whether the fact that females develop literacy skills at an earlier age than males (Beswick, Willms, \& Sloat, 2005) is a confounding factor is harder to resolve.

Strictly developmental approaches also underemphasise the significance of affective factors. Advances in neurobiological research indicate that achieving higher-order creativity requires heightened awareness of the relationship between body, mind and environment (Connolly, 2006). To accept the definition of creativity as a sophisticated, yet practicable, state of hyper-competence attained through ongoing expansion and enrichment of cognitive processes and schemata is, therefore, to accept that developmental discourses lack the complexity re- quired to explain subtle, but crucial, interplays of personal and social factors which determine whether creativity is enabled or impeded in individual cases.

\section{The Psychometric Discourse: Education as Socialisation}

The definitive feature of psychometric approaches to creativity is reference to, or reliance upon, an individual's likelihood of generating significant creative output as a function of social, psychological and intellectual traits/characteristics (Calderon et al., 2007; Treffinger \& Isaksen, 2005).

A second diagnostic, but non-essential, element of the psychometric perspective is its tendency to emerge in settings where actualisation hinges on interactions between individuals. Klijn and Tomic (2010) suggest that, in such settings, cognition is necessary, but not sufficient, to effect creative outcomes: Although those who participate in creative industries are advantaged if they possess fluency, originality, flexibility, imagination, field independence, knowledge of heuristics and a tendency to self-regulate, interactions that cultivate conflict, rather than co-operation, preclude actualisation.

Attempts to identify social structures and practices that facilitate creative co-operation often foster interest in alternative cultures and practices. It has been suggested, for example, that liminality (defined as a manifestation of both institutional and anti-institutional characteristics) (Lindsay, 2010) and strategic, targetted interventions (Loi \& Dillon, 2006) provide opportunities to capitalise on periodic, ephemeral triggers to generate creative insights and breakthroughs.

Such receptivity to novel social practices conveys benefits, but it can also result in loss of distinction between creative and non-creative individuals, processes and products. In attempting to counter loss of rigor and eliminate ambiguities, Cropley and Cropley (2010) have proposed that what distinguishes true creativity from pseudo-creativity (when novelty derives solely from non-conformity, lack of discipline, blind rejection of what already exists and a personal letting go) and quasi-creativity (having elements of true creativity, but only a tenuous connection with reality) is a connection to reality that renders the product useful, valuable, appropriate and correct.

Recognition that issues of utility and function must be objective, as well as subjective, initiates a reconciliation of the psychometric view of creativity with Sternberg's contention that generation of creative output requires individuals to pass through three stages: 1) Analysis of possibilities to determine which ideas are worth pursuing and which are not; 2) Escape from the bounds of conventional thinking to see problems in new ways and; 3) A practical-contextual stage involving realisation of new ideas and persuading others of their value (Sternberg \& Lubart, 1999).

Claxton (2006) completed the process of reconciliation when he recognised that the experiences of individuals are rendered social by filtration through four intrapersonal domains: 1) a genetic domain composed of what one is biologically capable of doing and the extent to which one is able to do it well, or poorly; 2) a domain of momentary, sensory memory or experience; 3) a skillscape, in which the individual interprets and reacts to the events they are experiencing and; 4) a wordscape formed from the ability to articulate and share one's understanding of events and experiences. This establishes the psychometric discourse of creativity as one that is concerned with controlled socialisation; aimed at cultivating creative products 
of both individuals and groups (Figure 1).

\section{Limitations of the Psychometric Discourse}

As for developmental discourses, the psychometric perspective is valid only to the extent that it is consistent with neurobiological phenomena. Mrazik and Dombrowski (2010) interpret neurobiological evidence within an openly psychometric framework, and speculate that, like other quantitative, polygenic traits, an individual's capacity for creative output is likely to be determined by interactions between genetics and environment. Noting that specific alterations in brain structures and features have been linked to different disorders or dispositions, and that prenatal (specifically second and third trimester) exposure to specific stimuli are known causes of psychological abnormalities, the authors suggest that positive outcomes, such as enhanced creativity, might also be linked to prenatal events. A growing list of behavioural and psychological traits found to be under at least some degree of genetic control (Mrazik \& Dombrowski, 2010) provides strong support for genetic theories of creativity, but there are dangers associated with any approach that focusses on individuals who represent only the extremes of human variation.

The tendency for creativity studies to oscillate between extremes of breadth or detail has been criticised by Feldman and Benjamin (2006): Focussing on the specific example of a movement to decouple tests for creativity and tests for IQ, the authors question the potential of any methodology that separates the individual from the domain and field of operation. This is a crucial point. If the purpose of psychometric methods is to understand how and why individual factors affect creativity, the fact that creative output varies in unexpected, unpredictable ways (even in highly controlled environments that have been engineered for creative purposes) suggests that a purely psychometric approach has limited utility.

\section{The Sociocultural Discourse: Education as Administration}

The importance of social environment is a recurrent theme in educational theory and sociocultural discourses of creativity represent a continuation of the tradition. In this case, the focus is not on processes that shape individual perceptions, but the sociocultural forces that draw attention to creativity in the first instance (Figure 1).

A link between education and work has been recognised by industrialised nations for over 200 years and, in developed countries, formal education has long been viewed as a means of preparing individuals for participation in civic life (Dewey, 1916). Until the 1970's, this was a relatively straightforward process where individuals received a single round of education/training that equipped them for a long, stable career in a particular industry or profession (Kilpatrick \& Allen, 2001). Since this time however, rapid globalisation has produced a situation where economic instability drives recurrent cycles of growth and recession; rendering individuals vulnerable to recurrent periods of unemployment and in need of recurrent retraining (Smith et al., 2001; Kilpatrick \& Allen, 2001).

The nature of public debate is such that discourses based on critical analysis of sociocultural trends tend to be dismissed as irrational resistance to change, or misguided attempts at political correctness (Groundwater-Smith et al., 2007). This is an ill-informed, and overly simplistic, view that fails to recognise the full transformative potential of quality education. To illustrate the point, it is useful to examine academic and administrative responses to previous reforms centred on the issue of lifelong-learning.

Emerging in the wake of a global recession in the early 1990's, the lifelong learning movement was initially justified through reference to statistics showing that the level of basic education required for participation in the workforce increases each year (Belanger, 1999; Kilpatrick \& Allen, 2001) and increasing levels of education lead directly to increased socioeconomic status (Carnoy, 1999; Kilpatrick \& Allen, 2001).

Challenges to the rhetoric of lifelong learning arose not because there were issues of educational or economic merit: Education professionals openly acknowledge that individuals often perform better in learning programmes as adults (compared to when they were adolescents and children) because they are motivated by a sense that their course of study is relevant to their own life and goals (Imel, 1998) and purely economic analyses indicate that only by promoting equitable outcomes can governments increase productivity and revenue, and decrease crime and reliance on government financial support (Smith et al. 2001).

The problem, as identified by critics, stemmed from the ideological implications of forcing individuals to assume personal responsibility for maintaining and upgrading the skills and knowledge brought to the workplace (Forrester et al., 1995; Foley, 1999; Bagnall, 2001; Billett, 2001). Framing the problem relative to three primary discourses of lifelong learning that featured prominently in public debate, Bagnall (2001) demonstrated that while all three shared an apparent commitment to individual liberation and personal development, each was in fact a construct of government and/or industry that was being manipulated to privilege some sectors of the community through the exploitation of others (Bagnall, 2001).

Informed resistance to reforms focussed on increasing creativity in primary and secondary schooling (Alan, 2002; Craft, 2006a; Geist \& Hohn, 2009; Lehane, 2008; Longo, 2010; Shaheen, 2010; Taylor, Jones, Broadwell, \& Oppewal, 2008; Woronov, 2009; Zhao, 2006) suggests that the value of different forms of scholarly and vocational output continues to be controlled by a relatively small number of privileged individuals. The sociocultural discourse of creativity should be recognised for what it is: A domain of critical, reflective praxis that challenges policies and practices with the potential to generate or perpetuate social and economic inequity (Dewey, 1916).

\section{Limitations of the Sociocultural Discourse}

The most obvious limitation of sociocultural discourses is a lack of linkage, and sometimes outright conflict with, proven teaching and learning strategies. The constructivist notion of the zone of proximal development, for example, requires learning environments structured to provide all students (regardless of their current level of ability) with the opportunity to extend their knowledge and conceptual understanding through interaction with others (DuVall, 2001; Hamza \& Wickman, 2008, 2009; Jakobsson, Akitalo, \& Aljo, 2009; Newton \& Newton, 2009; Sakai \& Leggo, 1997). At face value, this would appear consistent with the idea of education as preparation for full and equal participation in civic life.

Transcripts of conversations between, and interviews with, teachers and students who have developed and applied peer- 
scaffolding approaches however, suggest that rather than encouraging individuals to develop their own understanding, the net effect often reduces to a validation-by-consensus mentality (Capraro, Kulm, \& Capraro, 2005; Chin \& Chia, 2004; Demirci, 2008; Gautier, Deutsch, \& Rebich, 2006; Hamza \& Wickman, 2008; Mills et al., 2008; Nehm \& Reilly, 2007; Newton \& Newton, 2009; Psycharis \& Babaroutsis, 2005; Salierno, Edelson, \& Sherin, 2005; Settlage, 2007; Smith \& Abell, 2008; Stamp, 2007; Stamp \& Armstrong, 2005; Wali Abdi, 2006).

This does not mean that deployment of peer-scaffolded learning cannot deliver substantial learning gains for individuals. It simply highlights the fact that quality teaching requires practitioners with the skills, knowledge and experience to design and implement learning programmes that draw on many different teaching strategies. Sociocultural discourses are useful when seeking to refine and improve educational policies and practices. To move beyond problematisation and develop appropriate, effective and contextualised solutions however, requires integration with other discourses.

\section{The Entrepreneurial Discourse: Education as Commercialisation}

Where developmental, psychometric and sociocultural discourses are concerned primarily with the person and process aspects of creativity, the entrepreneurial discourse focusses on products (Figure 1).

In fields of endeavour where those products have market value, cost-benefit approaches may be applied to develop frameworks for identification, support and reward of those that generate the most, or most valuable, output (Penaluna, Coates, \& Penaluna, 2010). An outcomes-based approach of this nature is compatible with knowledge-creation cultures (Katehi \& Ross, 2007) and can be implemented in ways that emphasise constructive, rather than competitive, social interactions (Ogilvie \& Simms, 2009), but it also encourages the imposition of arbitrary limitations on what is recognised and validated.

\section{Limitations of the Entrepreneurial Discourse}

In corporate communities, overt discrimination against any particular sector of society is inviable because it constrains market size, and therefore limits profit, but this is not the case in education. Exposure to market forces has in fact, led to a rise in discriminatory practices in the tertiary sector and analysis of responsive trends provides powerful insights into how entrepreneurial frameworks function.

Repeal of government funding to tertiary institutions over the past twenty years has meant that many are repositioning themselves as providers of educational products (Clegg, 2008; Hargreaves \& Shirley, 2009; Milbrandt \& Milbrandt, 2011). As corporate and industrial interest in creativity is also increasing, universities are pressured to design and implement education and training programmes that develop creative skills and/or confer a creative edge (Milbrandt \& Milbrandt, 2011).

While pressure to design and implement more rigorous educational programmes has no doubt enhanced quality of instruction and assessment in several fields (Kleiman, 2008; Kowaltowski, Bianchi, \& Paiva, 2009), it also introduces new challenges which are being met by responses that expose inconsistencies within and among institutions. Moves toward specialised (branded) undergraduate programmes and research insti- tutes for example, have been challenged on grounds that this is incompatible with maintenance of academic standards and opposes the fluid, dynamic interactions that make creativity possible (Beghetto \& Kaufman, 2009). At the same time however, institutions with strong academic reputations have proposed that they should be granted exclusive rights to offer doctoral programmes (Nerad \& Heggelund, 2008). Both positions assume that creativity is synonymous with academic success, but this is both untrue and the root cause of many unethical and dysfunctional practices.

Drawing on evidence that creative individuals tend to be receptive to the ideas and practices of others, Da Silva and Davis (2011) have argued that academics who regularly attend conferences, cross-faculty and/or cross-disciplinary meetings etc. are more likely to generate creative output than those who prefer less social modes of operation. Although the authors demonstrate a positive correlation between "absorptive capacity" (interaction with others) and publication rate (academic success), their results do not prove that absorptive capacity is correlated with creativity.

The quantitative link between academic rank and publication rates is well-documented (DaSilva \& Davis, 2011), but rarely subjected to critical analysis. There is no evidence that academics who do not publish are incapable of creativity and several lines of evidence suggest that these individuals are simply disadvantaged by prevailing social practices (Jeffrey, 2006). It is, in fact, possible that higher publication rates are more reflective of managerial skills than academic or creative ability (Clegg, 2008).

Recognition that production does not necessarily equate to creation is more common in the artistic sector. Walling (2009) for example, notes that the rise of digital technologies (particularly those with pre-loaded content) make it possible to generate copious quantities of imitative work, but tempers this with recognition that imitative stages are important for skill development. Tillander (2011) goes further still; suggesting that as digital technologies become more advanced, the situations and contexts in which they are employed will inevitably generate unanticipated forms of creation.

Overall, the evidence suggests that while an entrepreneurial approach is functional in technical and corporate settings, academic and educational organisations are dependent on moral and ethical frameworks that break down when forced to operate under the impetus of competitive attainment (Clegg, 2008; Craft, 2006b).

The impact of such breakdown may not become apparent for some time. As academics from diverse disciplines are pressured to establish credibility within education, a tendency to approach teaching positions as opportunities to avoid the perils of funding-dependent salaries, or obtain academic merit points (Reising, 2008) is resulting in nominal reclassification of academic personnel as teaching and learning experts (Kean, Mitchell, \& Wilson, 2008). A resultant failure to attract and retain educators with working knowledge of the various philosophies of education, and the ways that these are situated relative to individuals, communities and nations, may well eradicate the reflexive, locally developed solutions to local issues and problems that are a hallmark of quality education (Hargreaves \& Shirley, 2009).

\section{Perceptions of Scientific Creativity}

Determining which conceptualisation of creativity has great- 
est relevance in science is not straightforward. Culross (2004) has argued that increasing global emphasis on collaborative, multidisciplinary research means the historical stereotype of the $\mathrm{BC}$ individual working alone on a research project of their own devising is no longer functionally viable. Braben (2004) however, contends that large scale corporatization/commercialisation of research funding and facilities itself is the single greatest threat to future creativity and innovation.

Braben's (2004) concerns are not unfounded. Enforced collaboration can lead to unfocussed, ineffective experimentation and research (Bore, 2006; Goran \& Braude, 2007) and there is evidence of declining quality and originality of intellectual output at postgraduate and post-doctoral levels (Holligan, 2005; Jackson, 2004; Medina, 2006). Superficial economically-motivated reform of educational policies and practices is therefore unlikely to solve the underlying problems, which originate from a failure to confront inconsistencies in perceptions and practice.

Heilbron (1992) has examined lexicographic evolution of creativity studies and notes that elements of key terminology have undergone radical transformations in recent decades. The word "genius" for example, originally served as collective noun relating to a communal state of transcendental insight; but has become reified as the result of processes concerned with establishing and defending a system of intellectual stratification based on quantitation of comparative ability or attainment. Although the process of reification may have been conceived and enacted with the innocuous (even noble) intention of overcoming post-Darwinian reservations regarding the moral and social value(s) of science and scientists (Heilbron, 1992), it has insidious implications.

Insistence that creativity is an ephemeral, nebulous trait personified in a relatively small subset of élite individuals is dysfunctional at a societal level because there is not, and cannot be, delineation of a single creative archetype. Creativity in any domain of human endeavour can be correlated with a range of personal traits and characteristics, including self-motivation, risk-taking, suspension of belief, curiosity, attention to detail, self-reliance, individualism, patience and an ability to cope with loneliness (Anderson, 1996; Boden, 2001; Chandler, 1999; Christine \& Glenn, 2007; Csikszentmihalyi, 1990; Davis, 2005; Erez, 2004; Gilbert, 2007; Goodenough, 1993; Herbert, 2001; Kleiman, 2008; Medina, 2006; Miller, 2000; Sarath, 2006; Simon, 2001; Simonton, 2003); but its actualisation is the product of complex, dynamic interplay between personal and societosocial characteristics (Chandler, 1999).

The mythology of creativity that has emerged in the 20th and 21st centuries is also inconsistent with the neurobiological processes that underpin human cognition. As long as a fundamental level of verbal and spatial/mathematical (i.e. language, literacy and numeracy) proficiency is attained, the capacity for both "scientific" and "artistic" creativity exists within all individuals (Simon, 2001). The crucial ingredient for realisation is not possession of innately superior neurochemical or neurobiological structures or schemata, but access to opportunities to refine and improve speed and processing capacity (Simon, 2001). The positioning and practice of science as distinct from other areas of liberal intellectualism however, means that very few, if any, individuals are granted full and equal access to those opportunities (Simon, 2001).

In practice, science and scientists operate within a mosaic of ever-narrowing subfields, where antithetic achievements such as mastery of domain-specific knowledge are exulted and rewarded (fiscally and socioculturally) far more generously than genuine creativity (Bore, 2006; Braben, 2004; Goran \& Braude,
2007; Holligan, 2005; Jackson, 2004; Medina, 2006). The reasons for this are deeply entrenched in, and reinforced by, the culture of contemporary practice.

\section{The Reality of Scientific Practice}

The notion of scientific knowledge as valid only when canonised through publication is enforced very early in education and training. Russ et al. (2009) found that, at the high-school level, students and teachers invariably evaluate the validity of ideas and explanations through consultation of textbooks, or other expert repositories, in the first instance. While consultation of published text has heuristic merit, excessive dependence on external verification of ideas can be counterproductive, leading to conceptualisation of scientific ability as focussed on recall of facts and technical/practical skill (Newton \& Newton, 2009) rather than the ability to extend and reconfigure understanding when confronted with novel problems.

A recent review of perspectives and challenges in science education indicates that a belief that there is, and can only ever be, one valid, scientific "way of knowing" is widespread; and that the root cause is a lack of alignment between science education/educators and scientific practice (Kind \& Kind, 2007). It is however, naive to assume that practitioners of research are any less dogmatic than students and teachers.

Individuals draw their understanding of what it is, and what it means, to be a scientist from a diverse array of sources: From interactions with educators and colleagues in school/university and the workplace, to general media reports, editorial articles in prominent journals, weblogs from practicing scientists and popular-science books (e.g. Peter Doherty's 2003 A Beginner's Guide to Winning a Nobel Prize). Perhaps one of the most iconic, mimetic articulations of the operational reality is Professor Peter Medawar's (1967) The Art of the Soluble. In this, and a follow-up publication titled Advice to a Young Scientist (1979), Medawar advocates a pseudomathematical approach which focusses on a zone of optimal difficulty (The Medawar Zone). Medawar proposed that those wishing to succeed in science could best achieve this goal by honing in on problems within this zone because solving problems that were too simple would yield insufficient rewards, and solving problems that were exceedingly difficult was pointless because others would not recognise and reward their achievements.

Medawar's contribution is historically and culturally significant because it is a clear and unambiguous validation of the perception that scientific success should be quantified in peer-mediated terms such as publication and citation rates, funding levels et cetera. For practicing scientists, this means that real currency is not the quality and originality of one's work per se, but the value attributed to it by one's peers.

Peer-review of manuscripts and grant/funding applications is firmly entrenched as best-practice in relation to assessing merit (Australian_Research_Council, 2008; De Groote, 2008; Moore, 2009a, 2009b; Pool, Macy, McManus, \& Noh, 2008; Simon, 2001; Simonton, 2003; Wilkinson, 2009) and, although there is growing awareness of fundamental flaws in peer-review systems, reliance on publication/citation as the primary index of quality is persistent and pervasive (Hoffmann, 2008; Jerome, 2008). Peer review has become incorporated into both secondary and tertiary science education programmes (Bower \& Richards, 2006; Bulte, Westbroek, De Jong, \& Pilot, 2006; Reynolds \& Moskovitz, 2008; Santucci et al., 2008), postgraduate 
students are indoctrinated with a "publish or perish" mantra (Caon, 2008a, 2008b) and the formation of ostensibly collaborative, covalidating professional networks or conglomerates is both implicitly and explicitly espoused as more meaningful than small-scale, independent research (Australian_Research_Council, 2008; Carpenter et al., 2009; Feller \& Cozzens, 2008; Santucci et al., 2008; Wilkinson, 2009). In this sense, the operational reality of science is not necessarily dissimilar to other fields of endeavour, but as long as there is apposition of perceived and proximal realities, there is little hope of lasting commitment to policies and practices capable of facilitating genuine creativity (Schmidt, 2010).

In an academic context, the peer-validation culture is problematic because it leads practitioners to assume that meaningful learning/progress is confined to discovery of new content (Jacob, 2001). To suggest that this is all that is permissible in science is however, ideologically offensive; in the same sense that attempts to "quantify" the creative output of different races (Lynn, 2007) are offensive because they arbitrarily elevate a single way-of-being above others.

The idea that the value of scientific output can be assessed only by those who have proven proficiency in the field is entirely consistent with Popper's statement that progress occurs through systematic identification and extension of the limits of existing theory (Popper, 1959). When decoupled from an understanding that anomalies and contradictions are indications that existing schemata require reevaluation/reconfiguration, or abandonment (Kuhn, 1962) however, the system ceases to function. Some degree of isolation or liberation from the constraints of contemporary culture is therefore essential for creativity and is for this reason that many of the most transformative advances come from individuals that operate, at least initially or temporarily, on the margins of their field.

The necessity of ruptures with prevailing theories and practices has been analysed in the context of geographical studies; where Barnes (Barnes, 2004) employs Fouccalt's idea of heterotopian loci as initially independent intellectual positions beyond the realm of accepted practice which are colonised by an increasing number of individuals as the meme takes hold. It is interesting to note that Barnes' analysis implies that exponential advances in technology could serve to accelerate the process of incorporation of heterotopian perspectives, but there is also the potential to reinforce the boundaries of the self-authenticating status quo.

This idea is explored in detail by Ramachandran (Ramachandran, 2006), who proposes that those who extend their domain of practice beyond accepted boundaries are often ostracised; and that this ostracism is justified by a belief that skepticism is essential to good scientific practice. Ramachandran (Ramachandran, 2006) challenges this as destructive to progress, and to the idea that science can and should be an enjoyable pursuit, but how well, or how poorly, an individual copes with ostracism is a critical element in enabling or disabling creative output.

Simonton (Simonton, 2003) places great emphasis on the role of aberrant, dysfunctional logic and acknowledges that tension between individual and collective perceptions is often the genesis of transformative breakthroughs. In this sense, Simonton delivers the only truly viable conceptualisation of creativity: As an inherently stochastic trait where the likelihood of creative output is increased when individuals have an extensive repertoire of responses to a given intellectual or technical problem.

\section{Resolving Tensions between Perceptions and Practice}

Traditional models of teaching and learning have done much to cultivate perceptions of science as a non-creative endeavour. Overt emphasis on rote-learning and rigid, dogmatic adherence to rules of the discipline are not only deterrents for students (Barak \& Shachar, 2008; Barton et al., 2008; Kessels et al., 2006; Latu \& Young, 2004; Lunn \& Noble, 2008; Timms et al., 2006); they are fundamentally incompatible with the true nature of science (Lee, Pierce, Talburt, Wang, \& Zhu, 2007; McLaughlin, 2006; Niaz, 2008; Reeves, Chessin, \& Chambless, 2007).

As conceptualisations of creativity mature, the boundaries between developmental, psychometric, sociocultural and entrepreneurial discourses dissolve and distinctions between noncreative and creative individuals become meaningless because domain knowledge and higher-order procedural/strategic knowledge develop in tandem (Haigh, 2007; Shen \& Confrey, 2007; Skrok, 2007), as does the capacity for metaphoric thought and metacognitive reflection (Dahlman, 2007; Marshall, 2005; Otto, 2007).

One of the most dangerous and destructive practices in education generally is a tendency to oscillate between excessive and insufficient emphasis on fundamental skills. It is true that some degree of basic knowledge and conceptual understanding is a prerequisite for success in any field, but it is also important to realise that the value attributed to any specific manifestation of skill or knowledge is dependent on the social environment (Freebody, 1990; Gee, 1996; Harreveld, Baker, \& Isdale, 2008; Luke, 1992).

The naive and arrogant assumption that the skills and abilities essential for success in science are beyond the reach of all but an élite subset of the population for example, has a significant negative impact on students; many of whom enter the science classroom convinced that they possess no natural aptitude or ability (Pugh, Linnenbrink-Garcia, Koskey, Stewart, \& Manzey, 2009). In science, as in other fields, overturning dysfunctional, counterproductive practices must commence with cultivation of a progressive, inclusive culture that does not value any one form of knowledge, or knowledge expression, over others.

Students are deterred from enrolling in science subjects because the current operational reality insists that scientific knowledge is an innate, bivariate (present or not) trait that is invariably expressed in a single (validated/canonised) dialect. This is a tragicomic misconception generated through overreliance on subjective measures of sociocultural status that obliterate the individual's sense of control over their own intellectual activities and experiences.

This is particularly challenging for those working in highschool environments because, in addition to primary subject material, adolescents can also be distracted by complex interpersonal issues associated with access to material resources; relationships; identity; power and control; cultural adherence; social justice; and personal cohesion (Dohnt \& Tiggemann, 2006; Harreveld et al., 2008; Hawk, Vanwesenbeeck, Graaf, \& Bakker, 2006; Hollander, 2006; Ricciardelli, McCabe, Lillis, \& Thomas, 2006; Ungar et al., 2007). There can be no single, universal pathway to resolution of these tensions, but there is a substantial body of evidence that those who emerge with skills and abilities that allow them to function in the adult world are those who find a way to live comfortably with deficiencies and 
contradictions in themselves and their environment/s (Fondacaro et al., 2006; Garbrecht, 2006; Jung, 1964). It is for this reason that reforms centred on primary and secondary education must also be accompanied by genuine reform of tertiary science education.

Moves to establish teaching-only positions within universities have tremendous pedagogical potential. To fulfill their (purported) role as a bridge between science education and scientific practice (Kean et al., 2008; Libarkin, Elkins, \& St. John, 2009) however, these positions should be occupied by those capable of effective, sustainable praxis. At present, they tend to be preferentially offered to scientists/research personnel who are nominally reclassified as teaching staff. Although some appointees may possess some modicum of educational qualifications/experience, the prevailing trend is for these positions to be approached a means of obtaining academic merit points (e.g. Pollacia \& McCallister, 2009; Reising, 2008), rather than a genuine attempt to integrate the philosophies and practices of science and education.

As long as the majority of scientists, and a significant proportion of appointees to emergent teaching-only positions, continue to operate within an essentially selfish, nepotistic ideologue, the decline in creative capacity will remain unchecked because this reinforces a conceptualisation of scientists as being in possession of an exceedingly improbable, and entirely innate, combination of knowledge and technical skill (Loehle, 1990). The absurdity of such exclusionary, hegemonic perceptions is that they perpetuate outdated, dysfunctional perceptions of science as incomprehensible and inaccessible to any but a select(ed) few of the most gifted individuals.

\section{Summary}

Surveys of student and public perceptions consistently indicate a lack of awareness/appreciation of science as a creative endeavour. This is a significant deterrent to students and is inconsistent with the nature of science as a dynamic, multidisciplinary undertaking where ideas and concepts are non-static entities that can, and should, change when contradicted by experimental evidence. To reverse the trend of declining enrolments in science subjects requires recognition that education takes place within distinct, but overlapping, discourses of creativity. Policies and practices that draw on any single discourse are counterproductive because they constrain creative output at all levels. If science education is to support creative output the dicourses of creativity must be integrated in ways that allow, and require, students to:

1) Acquire a high level of domain specific knowledge;

2) Practise the application of that knowledge in developing solutions to problems across a gradient of difficulty and;

3) Be challenged to link their knowledge of science to their knowledge of other fields as required to pursue and solve problems of relevance/interest to them.

Early theories of creativity aimed to elucidate relationships between individuals (person), process and product. Contemporary creativity studies however, can be categorised as reflective of four central themes, or discourses: The notion of creativity as the culmination of a uniquely personal journey (Developmental/Individuation), attempts to quantify personal and psychological traits that correlate with creative output (Psychometric/Socialisation), investment in creativity as a means of securing social and economic stability (Sociocultural/Administration) and the generation of products with technological or commer- cial value (Entrepreneurial/Commercialisation). Each discourse has advantages and disadvantages, depending on what it is the practitioner wishes to achieve. To translate theories of creativity into teaching and learning practice, a combination of developmental, psychometric and sociocultural perspectives (combining praxis, pedagogy and policy) has greater utility than application of the entrepreneurial approach (focus on profit).

\section{Acknowledgements}

Dr. Christine McDonald (Science Education, Griffith University) provided helpful suggestions in relation to an earlier draft. Collaboration and cooperative teaching with colleagues from the science teaching faculty of Holland Park State High School (Ms Beverly Haggett, Ms Cathy Menzler, Mr Peter Reddy, Ms Lisa James, Ms Kay Anderson, Ms Deanna Van Velsun and Mr Julian Bates) and The School of Veterinary Science at The University of Queensland (Dr Jennifer Seddon, Ms Joanne Gordon) informed and enriched many of the perspectives represented.

\section{References}

Al-Balushi, S. (2002). Correction fluid to correct your creativity. Science Activities, 38, 16. doi:10.1080/00368120209603627

Alan, L. (2002). The art of science. New Scientist, 176, 68.

Anderson, D. M. (1996). The science of creativity. Success, 43, 11.

Australian_Research_Council (2008). ARC future fellowships consultation paper. Canberra: Australian Research Council.

Bagnall, R. G. (2001). Locating lifelong learning and education in contemporary currents of thought and culture. In D. Aspin (Ed.), International handbook on lifelong learning. Dordrecht: Kluwer Publishing.

Barak, M., \& Shachar, A. (2008). Projects in technology education and fostering learning: The potential and its realization. Journal of Science Education and Technology, 17, 285-296. doi:10.1007/s10956-008-9098-2

Baran, G., Erdogan, S., \& Çakmak, A. (2009). A study on the relationship between six-year-old children's creativity and mathematical ability. International Education Studies, 4, 105-111.

Barker, P. (2008). Re-evaluating a model of learning design. Innovations in Education and Teaching International, 45, 127-141. doi:10.1080/14703290801950294

Barnes, T. J. (2004). Placing ideas: Genius loci, heterotopia and geography's quantitative revolution. Progress in Human Geography, 28, 585-595.

Barrow, L. H. (2006). A brief history of inquiry: From Dewey to Standards. Journal of Science Teacher Education, 17, 265-278. doi:10.1007/s10972-006-9008-5

Barton, A. C., Tan, E., \& Rivet, A. (2008). Creating hybrid spaces for engaging school science among urban middle school girls. American Educational Research Journal, 45, 68. doi:10.3102/0002831207308641

Beghetto, R. A., \& Kaufman, J. C. (2009). Intellectual estuaries: Connecting learning and creativity in programs of advanced academics. Journal of Advanced Academics, 20, 296-324. doi:10.1177/1932202X0902000205

Bélanger, P. (1999). Adult learning and the transformation of work. In M. Singh (Ed.), Adult learning and the future of work (pp. 19-28). Hamburg: UNESCO Institute for Education.

Ben-zvi-Assarf, O., \& Orion, N. (2005). A study of junior high students' perceptions of the water cycle. Journal of Geoscience Education, 53, 366.

Beswick, J. F., Willms, J. D., \& Sloat, E. A. (2005). A comparative study of teacher ratings of emergent literacy skills and student performance on a standardised measure. Education, 126, 116.

Billett, S. (2001). Learning throughout working life: Interdependencies at work. Studies in Continuing Education, 23, 19-35. 
doi:10.1080/01580370120043222

Black, A. A. (2005). Spatial ability and earth science conceptual understanding. Journal of Geoscience Education, 53, 402.

Boden, M. (2001). Creativity and knowledge. In A. Craft, B. Jeffrey, \& M. Leibling (Eds.), Creativity in education (pp. 95-102). London: Continuum Publishing.

Bore, A. (2006). Bottom-up for creativity in science? A collaborative model for curriculum and professional development. Journal of Education for Teaching: International Research and Pedagogy, 32, 413-422. doi:10.1080/02607470600982019

Bower, M., \& Richards, D. (2006). Collaborative learning: Some possibilities and limitations for students and teachers. Proceedings of the 23rd annual ascilite conference: Who's learning? Whose technology? Sydney: University of Sydney.

Braben, D. (2004). Pioneering research: A risk worth taking. Hoboken, NJ: John Wiley \& Sons.

Bruning, R., Schraw, G., Norby, M., \& Ronning, R. (2004). Cognitive psychology and instruction (4th ed.). Upper Saddle River, NJ: Pearson Education Inc.

Bulte, A. M. W., Westbroek, H. B., De Jong, O., \& Pilot, A. (2006). A research approach to designing chemistry education using authentic practices as contexts. International Journal of Science Education, 28, 1063-1086. doi:10.1080/09500690600702520

Calderon, J., Subotnik, R., Knotek, S., Rayhack, K., \& Gorgia, J. (2007). Focus on the psychosocial dimensions of talent development: an important potential role for consultee-centered consultants. Journal of Educational \& Psychological Consultation, 17, 347-367. doi:10.1080/10474410701634302

Caon, M. (2008a). Getting published in australasian physical and engineering sciences. Australasian Physical \& Engineering Sciences in Medicine, 31, 424.

Caon, M. (2008b). Peer review: How to be a good reviewer. Australasian Physical \& Engineering Sciences in Medicine, 31, 13. doi:10.1007/BF03178594

Carnoy, M. (1999). The great work dilemma: Education, employment and wages in the new global economy. In J. Ahier, \& G. Esland (Eds.), Education, training and the future of work 1: Social, political and economic contexts of policy development (pp. 62-75). London: Routledge.

Capraro, M. M., Kulm, G., \& Capraro, R. M. (2005). Middle grades: Misconceptions in statistical thinking. School Science and Mathematics, 105, 165. doi:10.1111/j.1949-8594.2005.tb18156.x

Carpenter, S., Armbrust, E., Arzberger, P., Chapin, F., III, Elser, J., Hackett, E., Ives, A., Kareiva, P., Leibold, M., Lundberg, P., Mangel, M., Merchant, N., Murdoch, W., Palmer, M., Peters, D., Pickett, S., Smith, K., Wall, D., \& Zimmerman, A. (2009). Accelerate synthesis in ecology and environmental sciences. Bioscience, 59, 699. doi:10.1525/bio.2009.59.8.11

Carter, L. (2008). Sociocultural influences on science education: Innovation for contemporary times. Science Education, 92, 165-181. doi:10.1002/sce.20228

Chandler, R. (1999). Creative parallel spaces in science and art: Knowledge in the information age. Journal of Arts Management, Law, and Society, 29, 163-176. doi:10.1080/10632929909597301

Chin, C., \& Chia, L.-G. (2004). Problem-based learning: Using students' questions to drive knowledge construction. Science Education, 88, 707-727. doi:10.1002/sce.10144

Christine, C., \& Glenn, E. S. (2007). General, artistic and scientific creativity attributes of engineering and music students. Creativity Research Journal, 19, 213. doi:10.1080/10400410701397271

Clegg, P. (2008). Creativity and critical thinking in the globalised university. Innovations in Education and Teaching International, 45, 219. doi:10.1080/14703290802175982

Connolly, W. E. (2006). Experience \& experiment. Daedalus, 135, 67-76. doi:10.1162/daed.2006.135.3.67

Craft, A. (2006a). Fostering creativity with wisdom. Cambridge Journal of Education, 36, 337. doi:10.1080/03057640600865835

Craft, A. (2006b). Fostering creativity with wisdom. Cambridge Journal of Education, 36, 337-350. doi:10.1080/03057640600865835

Craft, A., Chappell, K., \& Twining, P. (2008). Learners reconceptualising education: Widening participation through creative engagement? Innovations in Education and Teaching International, 45, 235-245. doi:10.1080/14703290802176089
Csikszentmihalyi, M. (1990). Theories of creativity. Thousand Oaks, CA: Sage.

Culross, R. R. (2004). Individual and contextual variables among creative scientists: The new work paradigm. Roeper Review, 26, 126. doi:10.1080/02783190409554257

Dahlman, Y. (2007). Towards a theory that links experience in the arts with the acquisition of knowledge. International Journal of Art \& Design Education, 26, 274-284. doi:10.1111/j.1476-8070.2007.00538.x

DaSilva, N., \& Davis, A. R. (2011). Absorptive capacity at the individual level: Linking creativity to innovation in academia. The Review of Higher Education, 34, 355-379. doi:10.1353/rhe.2011.0007

Davis, R. M. (2005). Creativity in science: chance, logic, genius, and zeitgeist. Choice, 42, 874.

De Groote, S. M. A. (2008). Citation patterns of online and print journals in the digital age. Journal of the Medical Library Association, 96, 362. doi:10.3163/1536-5050.96.4.012

Demirci, N. (2008). Misconception patterns from students to teachers: an example for force and motion concepts. Journal of Science Education, $9,55$.

Dewey, J. (1916). Vocational aspects of education. Democracy and Education, 23, New York: The Free Press.

Dohnt, H. K., \& Tiggemann, M. (2006). Body image concerns in young girls: The role of peers and media prior to adolescence. Journal of Youth and Adolescence, 35, 135. doi:10.1007/s10964-005-9020-7

DuVall, R. (2001). Cultivating curiosity with comfort: Skills for inquiry-based teaching. Primary Voices K-6, 10, 33-37.

Endler, L. C., \& Bond, T. G. (2008). Changing science outcomes: Cognitive acceleration in a US setting. Research in Science Education, 38, 149-166. doi:10.1007/s11165-007-9042-0

Erez, R. (2004). Freedom and creativity: An approach to science education for excellent students and its realization in the Israel arts and science academy's curriculum. Journal of Secondary Gifted Education, 15, 133-140.

Feller, I., \& Cozzens, S. (2008). It's about more than money. Issues in Science and Technology, 24, 28

Foley, G. (1999). Back to basics: A political economy of workplace change and learning. Studies in the Education of Adults, 31, 181-196.

Fondacaro, M. R., Brank, E. M., Stuart, J., Villanueva-Abraham, S., Luescher, J., \& McNatt, P. S. (2006). Identity orientation, voice, and judgments of procedural justice during late adolescence. Journal of Youth and Adolescence, 35, 987-997. doi:10.1007/s10964-006-9035-8

Forrester, K., Payne, J., \& Ward, K. (1995). Lifelong education and the workplace: A critical analysis. International Journal of Lifelong Learning, 14, 292-305.

Freebody, P., \& Luke, A. (1990). “Literacies” programs: Debates and demands in cultural context. Prospect, 5, 7-16.

Garbrecht, L. S. (2006). Schools' influence on identity formation in a time of change. Educational Researcher, 35, 42-48. doi:10.3102/0013189X035009042

Gautier, C., Deutsch, K., \& Rebich, S. (2006). Misconceptions about the greenhouse effect. Journal of Geoscience Education, 54, 386.

Gee, J. (1996). Social linguistics and literacies (2nd ed., pp. 139-143). London: Falmer Press.

Geist, E., \& Hohn, J. (2009). Encouraging creativity in the face of administrative convenience: How our schools discourage divergent thinking. Education, 130, 141-140.

Gilbert, D. M. (2007). Creativity: Ethics and excellence in science. Choice, 45, 118

Goodenough, U. W. (1993). Creativity in science. Zygon, 28, 399. doi:10.1111/j.1467-9744.1993.tb01043.x

Goran, D., \& Braude, S. (2007). Social \& cooperative learning in the solving of case histories. The American Biology Teacher, 69, 80-84. doi:10.1662/0002-7685(2007)69[80:SCLITS]2.0.CO;2

Groundwater-Smith, S., Mitchell, J., \& Mockler, N. (2007). Learning in the middle years: More than a transition. Melbourne: Thomson.

Haigh, M. (2007). Can investigative practical work in high school biology foster creativity? Research in Science Education, 37, 123-140. doi:10.1007/s11165-006-9018-5

Hamza, K. M., \& Wickman, P.-O. (2008). Describing and analyzing learning in action: An empirical study of the importance of misconceptions in learning science. Science Education, 92, 141-164. 
doi:10.1002/sce.20233

Hamza, K. M., \& Wickman, P.-O. (2009). Beyond explanations: What else do students need to understand science? Science Education, 93, $1-24$.

Hargreaves, A., \& Shirley, D. (2009). The fourth way: The inspiring future for educational change. San Francisco: Corwin Press.

Harreveld, B., Baker, K., \& Isdale, L. (2008). Teachers' work in reading literacy across the curriculum in the senior phase of learning. Curriculum Journal, 19, 105-118. doi:10.1080/09585170802079538

Hawk, S. T., Vanwesenbeeck, I., Graaf, H. D., \& Bakker, F. (2006). Adolescents' contact with sexuality in mainstream media: A selection-based perspective. The Journal of Sex Research, 43, 352. doi:10.1080/00224490609552334

Heilbron, J. L. (1992). Creativity and big science. Physics Today, 45, 42. doi:10.1063/1.881322

Herbert, A. S. (2001). Creativity in the arts and the sciences. The Kenyon Review, 23, 203.

Hoffmann, R. (2008). A wiki for the life sciences where authorship matters. Nature Genetics, 40, 1047. doi:10.1038/ng.f.217

Hollander, D. (2006). Sex in the media: Links to behavior differ between white and black teenagers. Perspectives on Sexual and Reproductive Health, 38, 172. doi:10.1111/j.1931-2393.2006.tb00272.x

Holligan, C. (2005). Fact and fiction: A case history of doctoral supervision. Educational Research, 47, 267-278. doi:10.1080/00131880500287179

Imel, S. (1998). Using adult learning principles in adult basic and literacy education, Education Practice Application Brief. Office of Educational Research \& Improvement.

Jackson, S. A. (2004). Ahead of the curve: Future shifts in higher education. EDUCAUSE Review, 39, 10-18.

Jacob, F. (2001). Imagination in art and in science. The Kenyon Review, $23,113$.

Jakobsson, A., Akitalo, A. M., \& Aljo, R. S. (2009). Conceptions of knowledge in research on students understanding of the greenhouse effect: Methodological positions and their consequences for representations of knowing. Science Education, 93, 1-18.

Jeffrey, B. (2006). Creative teaching and learning: Towards a common discourse and practice. Cambridge Journal of Education, 36, 399414. doi:10.1080/03057640600866015

Jerome, R. M. M. (2008). Further developing the profession's research mentality. Journal of the Medical Library Association, 96, 287. doi:10.3163/1536-5050.96.4.003

Jung, C. G. (Ed.) (1964). Man and his symbols. New York: Dell Publishing.

Katehi, L., \& Ross, M. (2007). Technology and culture: Exploring the creative instinct through cultural interpretations. Journal of Engineering Education, 96, 89-90.

Kean, R., Mitchell, N., \& Wilson, D. (2008). Toward intentionality and transparency: Analysis and reflection on the process of general education reform. Peer Review, 10, 4.

Kessels, U., Rau, M., \& Hannover, B. (2006). What goes well with physics? Measuring and altering the image of science. British Journal of Educational Psychology, 76, 761-780. doi:10.1348/000709905X59961

Kilpatrick, S., \& Allen, K. (2001). Review of research: Factors influencing demand for vocational education and training courses. Adelaide: Australian National Training Authority.

Kim, K. H. (2005). Learning from each other: Creativity in East Asian and American education. Creativity Research Journal, 17, 337-347. doi:10.1207/s15326934crj1704 5

Kind, P. M., \& Kind, V. (2007). Creativity in science education: Perspectives and challenges for developing school science. Studies in Science Education, 43, 1-37. doi:10.1080/03057260708560225

Kleiman, P. (2008). Towards transformation: Conceptions of creativity in higher education. Innovations in Education and Teaching International, 45, 209-217. doi:10.1080/14703290802175966

Kowaltowski, D. C. C. K., Bianchi, G., \& Paiva, V. R. T. D. (2009). Methods that may stimulate creativity and their use in architectural design education. International Journal of Technology and Design Education, 20, 453-476. doi:10.1007/s10798-009-9102-z

Kuhn, T. S. (1962). The structure of scientific revolutions. Chicago: University of Chicago Press.

Latu, S., \& Young, A. (2004). Teaching ICT to pacific island back- ground students. 6th Australasian Computing Education Conference, Dunedin, 18-22 January 2004.

Lee, Y. W., Pierce, E., Talburt, J., Wang, R. Y., \& Zhu, H. (2007). A curriculum for a master of science in information quality. Journal of Information Systems Education, 18, 233-242.

Lehane, C. S. (2008). The democratic take. Education Next, 8, 56-59.

Libarkin, J., Elkins, J., \& John, K. St. (2009). Editorial: The evolution of JGE: Responding to our community's needs. Journal of Geoscience Education, 57, 165. doi:10.5408/1.3544260

Lindsay, D. M. (2010). Organizational liminality and interstitial creativity: The fellowship of power. Social Forces, 89, 163-184. doi:10.1353/sof.2010.0068

Loehle, C. (1990). A guide to increased creativity in research-Inspiration or perspiration? Bioscience, 40, 123. doi:10.2307/1311345

Loi, D., \& Dillon, P. (2006). Adaptive educational environments as creative spaces. Cambridge Journal of Education, 36, 363-381. doi:10.1080/03057640600865959

Longo, C. (2010). Fostering creativity or teaching to the test? Implications of state testing on the delivery of science instruction. The Clearing House, 83, 54-57. doi:10.1080/00098650903505399

Lunn, M., \& Noble, A. (2008). Re-visioning science "Love and passion in the scientific imagination": Art and science. International Journal of Science Education, 30, 793-805. doi:10.1080/09500690701264750

Luke, A. (1992). Literacy and work in "New Times". Open Letter, 3, 3-15.

Lynn, R. (2007). Race differences in intelligence, creativity and creative achievement. Mankind Quarterly, 48, 157-166.

Lyons, T. (2006). The puzzle of falling enrolments in physics and chemistry courses: Putting some pieces together. Research in Science Education, 36, 285-311. doi:10.1007/s11165-005-9008-z

Marshall, J. (2005). Connecting art, learning, and creativity: A case for curriculum integration. Studies in Art Education: A Journal of Issues and Research in Art Education, 46, 227-241.

McLaughlin, J. (2006). A gentle reminder that a hypothesis is never proven correct, nor is a theory ever proven to be true. Journal of College Science Teaching, 36, 60.

McWilliam, E., Poronnik, P., \& Taylor, P. G. (2008). Re-designing science pedagogy: Reversing the flight from science. Journal of Science Education and Technology, 17, 226-235. doi:10.1007/s10956-008-9092-8

Medina, M. Á. (2006). The pursuit of creativity in biology. BioEssays, 28, 1151-1152. doi:10.1002/bies.20498

Meier, D. K., Reinhard, K. J., Carter, D. O., \& Brooks, D. W. (2008). Simulations with elaborated worked example modeling: Beneficial effects on schema acquisition. Journal of Science Education and Technology, 17, 262-273. doi:10.1007/s10956-008-9096-4

Milbrandt, M., \& Milbrandt, L. (2011). Creativity: What are we talking about? Art Education, 64, 8-13.

Miller, A. I. (2000). Insights of genius: Imagery and creativity in science and art. Cambridge: Massachusetts Institute of Technology.

Mills, K. V., Herrick, R. S., Guilmette, L. W., Nestor, L. P., Shafer, H., \& Ditzler, M. A. (2008). Introducing undergraduate students to electrochemistry: A two-week discovery chemistry experiment. Journal of Chemical Education, 85, 1116. doi:10.1021/ed085p1116

Moore, A. (2009a). Editorial: A new look at the literature-Of understanding, being understood and the role of the review. BioEssays, 31, 3-4. doi:10.1002/bies.200990003

Moore, A. (2009b). Editorial: The garbage collectors-Could a particular sector of author-pays journals become silently acknowledged collectors of scientific waste? BioEssays, 31, 821. doi:10.1002/bies.200900095

Mrazik, M., \& Dombrowski, S. C. (2010). The neurobiological foundations of giftedness. Roeper Review, 32, 224-234. doi:10.1080/02783193.2010.508154

Nehm, R. H., \& Reilly, L. (2007). Biology majors' knowledge and misconceptions of natural selection. Bioscience, 57, 263. doi:10.1641/B570311

Nerad, M., \& Heggelund, M. (Eds.) (2008). Toward a global PhD? Forces and forms in doctoral education worldwide. Seattle: University of Washington Press.

Newton, D. P., \& Newton, L. D. (2009). Some student teachers' conceptions of creativity in school science. Research in Science and Technological Education, 27, 45. doi:10.1080/02635140802658842 
Niaz, M. (2008). What "Ideas-about-Science" should be taught in school science? A chemistry teachers' perspective. Instructional Science: An International Journal of the Learning Sciences, 36, 233249.

Ogilvie, D. T., \& Simms, S. (2009). The impact of creativity training on an accounting negotiation. Group Decis Negot, 18, 75-87. doi:10.1007/s10726-008-9124-z

Otto, S. (2007). Beneath and beyond Truth: Studying literary narratives to research human phenomena. International Journal of Research \& Method in Education, 30, 73-87. doi:10.1080/17437270701207801

Park_Rogers, M. A., \& Abell, S. K. (2008). The design, enactment, and experience of inquiry-based instruction in undergraduate science education: A case study. Science Education, 92, 591-607.

Penaluna, A., Coates, J., \& Penaluna, K. (2010). Creativity-based assessment and neural understandings a discussion and case study analysis. Education and Training, 52, 670-678. doi:10.1108/00400911011088971

Pool, J., Macy, M., McManus, S., \& Noh, J. (2008). An exploratory investigation of frequently cited articles from the early childhood intervention literature, 1994 to 2005. Topics in Early Childhood Special Education, 28, 181. doi:10.1177/0271121408321949

Popper, K. (1959). The logic of scientific discovery. London: Routledge.

Psycharis, S., \& Babaroutsis, C. (2005). Prospective teachers' conceptual understanding of phenomena related to thermal physics and its evaluation. Journal of Science Education, 6, 40.

Pugh, K. J., Linnenbrink-Garcia, L., Koskey, K. L. K., Stewart, V. C., \& Manzey, C. (2009). Motivation, learning, and transformative experience: A study of deep engagement in science. Science Education, 94, 1-27.

Ramachandran, V. S. (2006). Creativity versus skepticism within science. The Skeptical Inquirer, 30, 48.

Reeves, C., Chessin, D., \& Chambless, M. (2007). Nurturing the nature of science. The Science Teacher, 74, 31.

Reising, D. (2008). Nursing education research-how to use it to build your promotion and tenure case. Journal of Nursing Education, 47, 387. doi:10.3928/01484834-20080901-02

Reynolds, J., \& Moskovitz, C. (2008). Calibrated peer review assignments in science courses: Are they designed to promote critical thinking and writing skills? Journal of College Science Teaching, 38, 60.

Ricciardelli, L. A., McCabe, M. P., Lillis, J., \& Thomas, K. (2006). A longitudinal investigation of the development of weight and muscle concerns among preadolescent boys. Journal of Youth and Adolescence, 35, 168. doi:10.1007/s10964-005-9004-7

Runco, M. A., \& Chand, I. (1995). Cognition and creativity. Educational Psychology Review, 7, 243-267. doi:10.1007/BF02213373

Russ, R. S., Coffey, J. E., Hammer, D., \& Hutchison, P. (2009). Making classroom assessment more accountable to scientific reasoning: A case for attending to mechanistic thinking. Science Education, 93, 875-891. doi:10.1002/sce.20320

Sakai, A., \& Leggo, C. (1997). Knowing from different angles: Language arts and science connections. Voices from the Middle, 4, 26-30.

Salierno, C., Edelson, D., \& Sherin, B. (2005). The development of student conceptions of the earth-sun relationship in an inquiry-based curriculum. Journal of Geoscience Education, 53, 422.

Santucci, A. P., Lingler, J. P. R. N., Schmidt, K. P., Nolan, B. P., Thatcher, D. P., \& Polk, D. P. (2008). Peer-mentored research development meeting: A model for successful peer mentoring among junior level researchers. Academic Psychiatry, 32, 493. doi:10.1176/appi.ap.32.6.493

Sarath, E. (2006). Meditation, creativity, and consciousness: Charting future terrain within higher education. Teachers College Record, 108, 1816-1841. doi:10.1111/j.1467-9620.2006.00763.x

Schmidt, A. L. (2010). The battle for creativity: Frontiers in science and science education. BioEssays, 32, 1016-1019. doi:10.1002/bies.201000092

Seo, H.-A., Lee, E. A., \& Kim, K. H. (2005). Korean science teachers' understanding of creativity in gifted education. Journal of Secondary Gifted Education, 16, 98-105.

Settlage, J. (2007). Demythologizing science teacher education: Conquering the false ideal of open inquiry. Journal of Science Teacher
Education, 18, 461-467. doi:10.1007/s10972-007-9060-9

Shaheen, R. (2010). Creativity and education. Creative Education, 1, 166-169. doi:10.4236/ce.2010.13026

Shelby, S. C., Ferrier, F., Anderson, D., Burke, G., Hopkins, S., Long, M., Maglen, L., Malley, J., McKenzie, P., \& Shah, C. (2001). CEET stocktake. The economics of vocational education and training in Australia. Adelaide: NCVER, ANTA.

Shen, J., \& Confrey, J. (2007). From conceptual change to transformative modeling: A case study of an elementary teacher in learning astronomy. Science Education, 91, 948-966. doi:10.1002/sce.20224

Sigelman, C. K. (1999). Life-span human development (3rd ed.) Boston: Brooks/Cole Publishing Company.

Simon, H. A. (2001). Creativity in the arts and the sciences. The Kenyon Review, 23, 203-220.

Simonton, D. K. (2003). Scientific creativity as constrained stochastic behavior: The integration of product, person, and process perspectives. Psychological Bulletin, 129, 475-494.

doi:10.1037/0033-2909.129.4.475

Skrok, K. (2007). Formations of pupils' attitudes and behaviours in chemistry teaching/Formación de valores y actitudes de los estudiantes en educación química. Journal of Science Education, 8, 107.

Smith, S. R., \& Abell, S. K. (2008). Assessing and addressing student science ideas. Science and Children, 45, 72.

Stamp, N. (2007). Overcoming ecological misconceptions. URL (last checked 11 August 2008.

http://ecomisconceptions.binghamton.edu/misconceptions.htm

Stamp, N., \& Armstrong, M. (2005). Using “The power of story” to overcome ecological misconceptions and build sophisticated understanding. Bulletin of the Ecological Society of America, 86, 177-183. doi:10.1890/0012-9623(2005)86[177:UTPOST]2.0.CO;2

Sternberg, R. J., \& Lubart, T. I. (1999). The concept of creativity: Prospects and paradigms. In R. J. Sternberg (Ed.), Handbook of creativity (pp. 3-15). Cambridge: Cambridge University Press.

Stevenson, J. C. (1994). Vocational expertise. In J. Stevenson (Ed.), In cognition at work: The development of vocational expertise. Adelaide: National Centre for Vocational Education Research.

Stevenson, J. C., \& McKavanagh, C.W. (1993). Practice 10, Theory 5: An examination of the depth of learning. SET: Research Information for Teachers, 1993, 4.

Stredl, H. J., \& Rothwell, W. J. (1987). The ASTD reference guide to professional training roles and competencies (Chapter 12, Vol. 1). Amherst, Massachusetts: American Society for Training and Development HRD Press.

Sweller, J. (2009). Cognitive basis of human creativity. Educational Psychology Review, 21, 11-19. doi:10.1007/s10648-008-9091-6

Taylor, A., Jones, M., Broadwell, B., \& Oppewal, T. (2008). Creativity, inquiry, or accountability? Scientists' and teachers' perceptions of science education. Science Education, 92, 1058. doi:10.1002/sce.20272

Timms, C., Courtney, L., \& Anderson, N. (2006). Girls’ perceptions of advanced IT subjects: Are they boring and irrelevant? Australian Educational Computing, 21, 3-7.

Treffinger, D. J., \& Isaksen, S. G. (2005). Creative problem solving: The history, development, and implications for gifted education and talent development. Gifted Child Quarterly, 49, 342. doi:10.1177/001698620504900407

Ungar, M., Brown, M., Liebenberg, L., Othman, R., Kwong, W. M., Armstrong, M., \& Gilgun, J. (2007). Unique pathways to resilience across cultures. Adolescence, 42, 166.

Wali, A. S. (2006). Correcting student misconceptions. Science Scope, 29, 39.

Wilkinson, E. (2009). UK doctors hail research excellence results. The Lancet, 373, 368. doi:10.1016/S0140-6736(09)60119-7

Woronov, T. E. (2009). Practices of education reform in Beijing. Anthropology \& Education Quarterly, 39, 401-422. doi:10.1111/j.1548-1492.2008.00030.x

Yager, R. E., \& Akcay, H. (2008). Comparison of student learning outcomes in middle school science classes with an STS approach and a typical textbook dominated approach. Research in Middle Level Education, 31, 1-16.

Zhao, Y. (2006). Are we fixing the wrong things? Educational Leadership, 63, 28-31. 